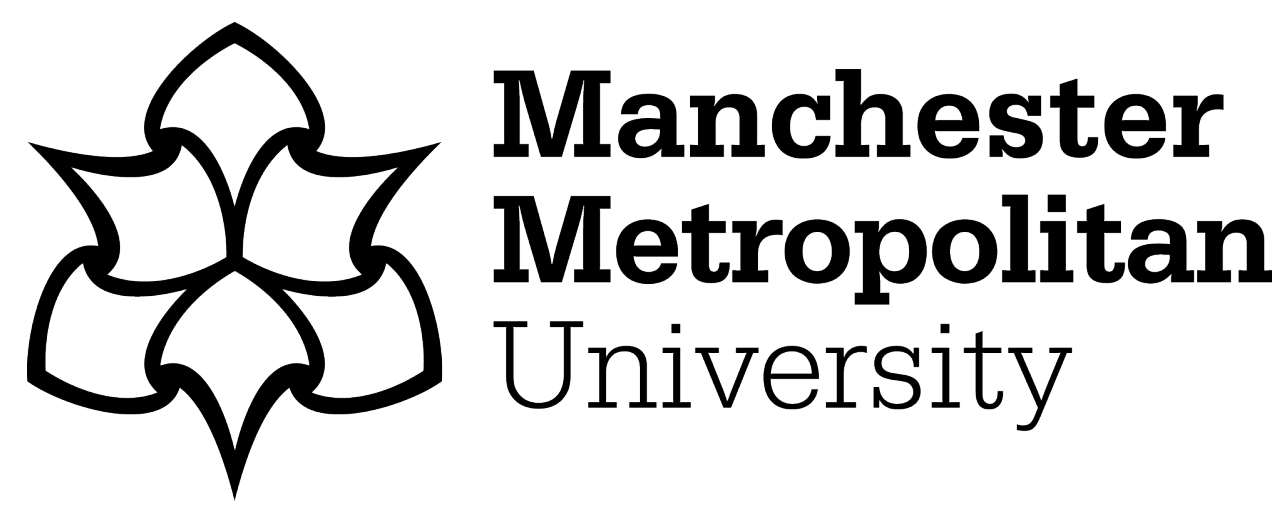

Ferreira, J, Lennox, GD, Gardner, TA, Thomson, JR, Berenguer, E, Lees, Alexander, Mac Nally, R, Aragão, LEOC, Ferraz, SFB, Louzada, J, Moura, NG, Oliveira, VHF, Pardini, R, Solar, RRC, Vieira, ICG and Barlow, J (2018) Carbon-focused conservation may fail to protect the most biodiverse tropical forests. Nature Climate Change, 8. p. 744. ISSN 1758-678X

Downloaded from: https://e-space.mmu.ac.uk/621348/

Version: Submitted Version

Publisher: Springer Nature

DOI: https://doi.org/10.1038/s41558-018-0225-7

Please cite the published version 


\title{
Carbon-focused conservation may fail to protect the most biodiverse tropical forests
}

\author{
Joice Ferreira ${ }^{1,18,19 *}$, Gareth D. Lennox ${ }^{2,18} \dagger$, Toby A. Gardner ${ }^{3,4,19}$, James R. Thomson ${ }^{5,6}$, \\ Erika Berenguer, ${ }^{7,2}$ Alexander C. Lees ${ }^{8,9}$, Ralph Mac Nally,10, Luiz E. O. C. Aragão ${ }^{11,12}$, \\ Silvio F. B. Ferraz ${ }^{13}$, Julio Louzada ${ }^{14}$, Nárgila G. Moura ${ }^{15}$, Victor H. F. Oliveira ${ }^{14}$, Renata Pardini ${ }^{16}$, \\ Ricardo R. C. Solar ${ }^{17}$ Ima C. G. Vieira ${ }^{15}$ and Jos Barlow ${ }^{2,14,15,19}$
}

As one of Earth's most carbon-dense regions, tropical forests are central to climate change mitigation efforts. Their unparalleled species richness also makes them vital for safeguarding biodiversity. However, because research has not been conducted at management-relevant scales and has often not accounted for forest disturbance, the biodiversity implications of carbon conservation strategies remain poorly understood. We investigated tropical carbonbiodiversity relationships and trade-offs along a forest-disturbance gradient, using unprecedented carbon and biodiversity datasets. Biodiversity was positively associated with carbon in secondary and highly disturbed primary forests. Positive carbon-biodiversity relationships dissipated at around $100 \mathrm{Mg} \mathrm{Cha}^{-1}$, meaning that in less disturbed forests more carbon did not equal more biodiversity. Simulated carbon conservation schemes therefore failed to protect many species in the most species-rich forests. These biodiversity shortfalls were sensitive to opportunity costs and could be decreased for small carbon penalties. To ensure that the most ecologically valuable forests are protected, biodiversity needs to be incorporated into carbon conservation planning.

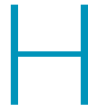
uman-mediated changes to the global climate system and biodiversity losses rank among the most intractable threats facing our species, and most others ${ }^{1,2}$. Given that tropical forests store $34 \%$ of the planet's terrestrial carbon ${ }^{3}$ and host two-thirds of its terrestrial biota ${ }^{4}$, the fate of these ecosystems will play a major role in shaping the outcomes of both the climate and biodiversity crises ${ }^{6}$. Indeed, climate change and biodiversity are inextricably linked in tropical forests: tropical species are directly threatened by rising temperatures and changing precipitation patterns ${ }^{7,8}$, while carbon storage is related, albeit uncertainly, to biodiversity levels ${ }^{9}$. As a result, failure to tackle both crises together will mean that neither can be dealt with adequately.

Growth in forest carbon conservation and implications for biodiversity. In recognition of the central role forests play in the carbon cycle, large financial commitments have been made to redirect economic incentives away from deforestation and forest degradation, and towards forest carbon protection. For example, between 2004 and 2015, governments and the private sector pledged almost US $\$ 10$ billion to the United Nation's Reducing Emissions from Deforestation and Forest Disturbance (REDD+) climate change mitigation mechanism ${ }^{10}$. The scale of this investment is at least one order of magnitude greater than previous levels of conserva- tion financing ${ }^{11}$ and is further bolstered by myriad other publicand private-sector initiatives that seek low-emissions development pathways in forest nations ${ }^{12}$. Rapid progress in high-resolution carbon mapping technologies, such as airborne $\operatorname{LiDAR}^{13}$ and the European Space Agency's BIOMASS Earth Explorer mission ${ }^{14}$, will facilitate these efforts and likely stimulate even greater interest in carbon conservation. While this growth in forest carbon protection is good news for climate change mitigation, the implications for biodiversity conservation are less clear ${ }^{15,16}$. Will investments seeking to maximize carbon stocks return commensurate biodiversity co-benefits? ${ }^{17}$ Or do unavoidable trade-offs mean that biodiversity conservation requires separate, bespoke financial instruments and planning approaches? ${ }^{18}$

The relationship between tropical forest carbon and biodiversity is fundamental to answering these questions. Although many studies have investigated patterns of carbon-biodiversity co-occurrence, the focus of most previous research has been at global and continental scales ${ }^{19-21}$. Given that implementation of carbon conservation schemes occurs at sub-national scales, by not accounting for variation at the scale at which decisions are made, such analyses offer limited insight into the biodiversity ramifications of carbon-focused projects. Moreover, tropical forests are subject to many local disturbances,

\footnotetext{
${ }^{1}$ EMBRAPA Amazônia Oriental, Belém, Brazil. ${ }^{2}$ Lancaster Environment Centre, Lancaster University UK. ${ }^{3}$ Stockholm Environment Institute, Stockholm, Sweden. ${ }^{4}$ International Institute for Sustainability, Rio de Janeiro, Brazil. ${ }^{5}$ Institute for Applied Ecology, University of Canberra, Canberra, Australian Capital Territory, Australia.. ${ }^{6}$ Arthur Rylah Institute for Environmental Research, Department of Environment, Land, Water and Planning, Melbourne, Victoria, Australia. ${ }^{7}$ Environmental Change Institute, University of Oxford, Oxford, UK. ${ }^{8}$ Division of Biology and Conservation Ecology, School of Science and the Environment, Manchester Metropolitan University, Manchester, UK. ${ }^{9}$ Cornell Lab of Ornithology, Cornell University, Ithaca, NY, USA. ${ }^{10}$ Sunrise Ecological Research Institute, Ocean Grove, Victoria, Australia. ${ }^{11}$ Tropical Ecosystems and Environmental Sciences Group, Remote Sensing Division, National Institute for Space Research, Sao Jose dos Campos, Brazil. 12 College of Life and Environmental Sciences, University of Exeter, Exeter, UK. ${ }^{13}$ Escola Superior de Agricultura Luiz de Queiroz, Universidade de Sao Paulo, Piracicaba, Brazil. ${ }^{14}$ Setor de Ecologia e Conserva cão, Universidade Federal de Lavras, Lavras, Brazil. ${ }^{15}$ MCTI/Museu Paraense Emílio Goeldi, Belém, Brazil. ${ }^{16}$ Instituto de Biociencias, Universidade de Sao Paulo, Sao Paulo, Brazil. ${ }^{17}$ Instituto de Ciências Biológicas, Departamento de Biologia Geral, Universidade Federal de Minas Gerais, Belo Horizonte, Brazil. ${ }^{18}$ These authors contributed equally: Joice Ferreira, Gareth D. Lennox. ${ }^{19}$ These authors jointly supervised this work: Joice Ferreira, Toby A. Gardner, Jos Barlow. *e-mail: joice.ferreira@embrapa.br. †e-mail: garethlennox@msn.com
} 

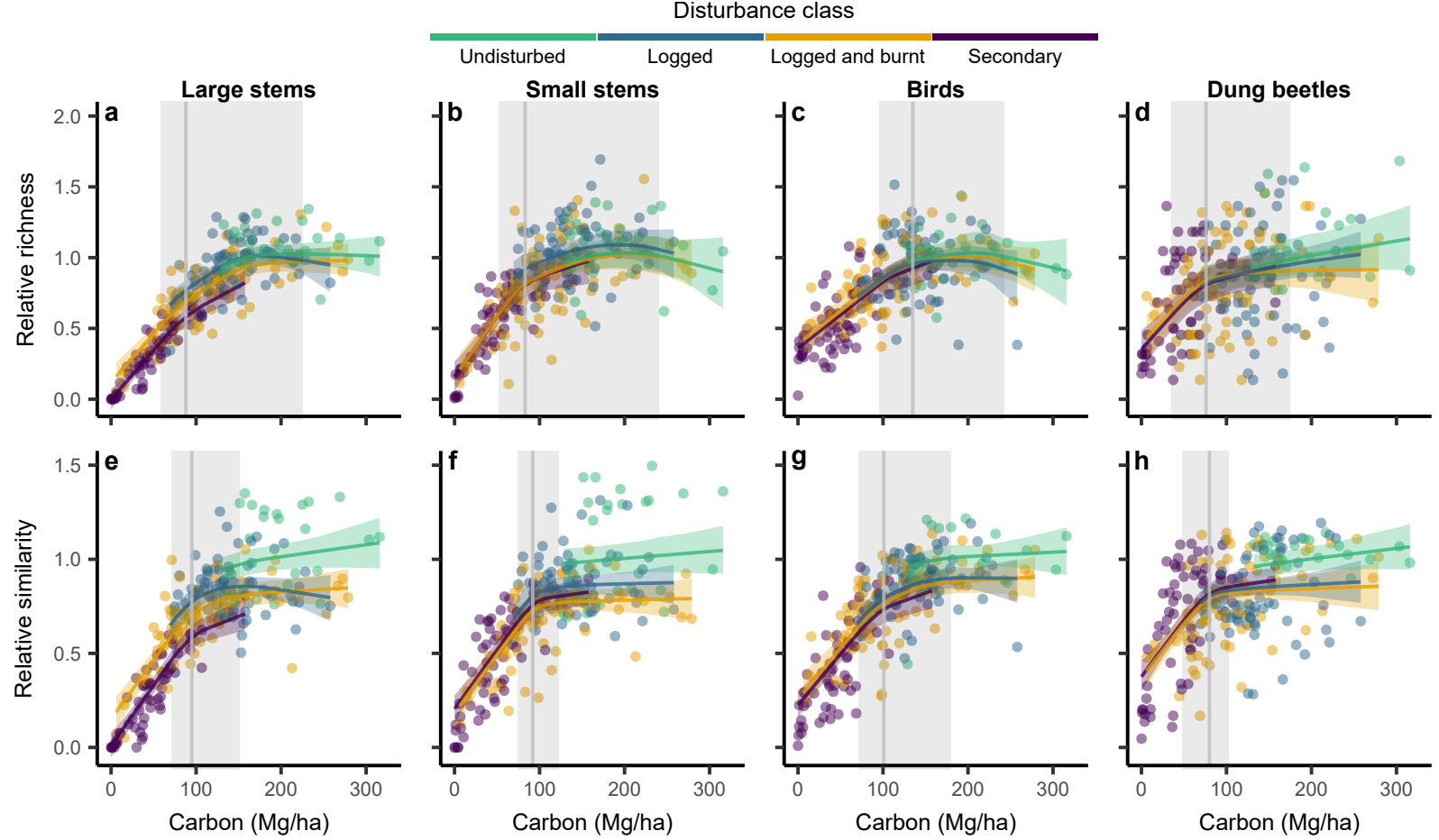

Fig. 1 | Carbon-biodiversity relationships in human-modified forests. a-h, The relationship between forest carbon levels and species richness (a-d) and compositional similarity to undisturbed forest (e-h) over disturbance classes for large stems (a and $\mathbf{e})$, small stems (b and $\mathbf{f})$, birds ( $\mathbf{c}$ and $\mathbf{g}$ ) and dung beetles ( $\mathbf{d}$ and $\mathbf{h}$ ). Species were identified using the convex hull species filter (see Methods). Richness and similarity values are given relative to their respective mean value in undisturbed forests. Points show the site values. Lines show the Bayesian piecewise linear splines. Error bands show 95\% credible intervals (see Methods). The grey vertical lines show the threshold estimate at which carbon-biodiversity relationships breakdown (see Methods). The grey window is the $95 \%$ threshold credible interval.

such as fire, logging and hunting ${ }^{22,23}$, resulting in substantial finegrained variation in ecological conditions ${ }^{24}$. Understanding the implications of this disturbance-mediated heterogeneity on the relationship between carbon and biodiversity is essential for designing effective conservation investments.

We investigated the extent to which carbon-biodiversity relationships depend on forest disturbance, then assessed the biodiversity implications of these relationships for carbon-focused conservation investments, using detailed and extensive tropical carbon and biodiversity datasets. In 234 eastern-Amazonian sites (site area $=0.3$ ha; Supplementary Fig. 1), we sampled, respectively, 1,537, 469 and 156 species of large- and small-stemmed plants, birds and dung beetles. The species we sampled differ in conservation importance. To account for this, we applied two species filters to our data to exclude species likely to be of low conservation value. We then weighted the remaining species by measures of conservation importance related to life-history traits (see Methods). Our study sites represent a comprehensive sample of anthropogenic-disturbance histories, and we grouped them into four disturbance classes relevant to forest governance policies: undisturbed forests $(n=30)$, logged primary forests $(n=70)$, logged and burnt primary forests $(n=75)$ and secondary forests $(n=59)$ (Supplementary Fig. 2).

We measured site-level biodiversity by species richness and compositional similarity to undisturbed forests. To characterize the carbon-biodiversity relationships, we fitted Bayesian piecewise linear models. We then used these models to calculate statistical thresholds in the carbon-biodiversity relationships and the proportion of biodiversity variation explained by carbon (coefficients of determination ( $R^{2}$ values); see Methods). Next, we formulated optimization models to assess the levels of biodiversity covered by carbon-maximizing conservation strategies across forestdisturbance classes. We calculated the relative difference in the species richness of the sites identified for protection when maxi- mizing carbon compared with when maximizing species richness; we call this difference the 'biodiversity shortfall' from a carbonmaximizing conservation strategy. We took two approaches to estimating biodiversity shortfalls that, by having different minimum species-occurrence requirements, differ in how conservatively species richness is measured (see Methods). We then investigated the nature of optimal carbon-biodiversity trade-offs over the disturbance gradient (see Methods). To focus on how the carbon-biodiversity relationships mediate the biodiversity effectiveness of carbon conservation schemes, in these optimizations, we first assumed constant conservation opportunity costs among sites. We then considered how the inclusion of economic factors may affect the results by incorporating variation in opportunity costs in two idealized scenarios. We first assumed that opportunity costs per unit carbon - that is, the price the conservation organization pays to conserve each $\mathrm{Mg} \mathrm{C}$ - increase with site carbon density. Such a situation could emerge when the most profitable alternative land use among sites is timber extraction and carbon-dense sites have larger stocks of economically valuable species. Second, we considered the case where opportunity costs per unit carbon decrease with carbon density. This can occur when sites face a deforestation threat - for example, for conversion to agriculture and opportunity costs per hectare are divided across larger stocks of carbon in sites with greater carbon density (see Methods).

Forest disturbance defines carbon-biodiversity relationships. Carbon-biodiversity relationships strongly depended on disturbance intensity (Fig. 1 and Supplementary Fig. 3). For forests retaining more than around $100 \mathrm{Mg} \mathrm{C} \mathrm{ha}^{-1}-$ the most species-rich forests - carbon and biodiversity were not statistically associated (Table 1 and Supplementary Table 1). In contrast, where carbon levels fell below around $100 \mathrm{Mg} \mathrm{C}^{-1}$, carbon and biodiversity were strongly and positively related. The carbon-biodiversity threshold relationship held across forest- 


\section{Table 1 | Carbon as a predictor of biodiversity in human- modified tropical landscapes}

\section{Richness Similarity}

\begin{tabular}{lll}
\hline Large stems & & \\
Undisturbed forests & 0.02 & 0.09 \\
Logged primary forests & $0.35^{\star}$ & 0.04 \\
Logged and burnt primary forests & $0.65^{\star}$ & $0.55^{\star}$ \\
Secondary forests & $0.85^{\star}$ & $0.79^{\star}$ \\
Small stems & & \\
Undisturbed forests & 0.01 & 0.05 \\
Logged primary forests & 0.03 & -0.02 \\
Logged and burnt primary forests & $0.39^{\star}$ & $0.46^{\star}$ \\
Secondary forests & $0.71^{\star}$ & $0.61^{\star}$ \\
Birds & & \\
Undisturbed forests & 0.01 & 0.08 \\
Logged primary forests & 0.04 & 0.08 \\
Logged and burnt primary forests & $0.24^{\star}$ & $0.37^{\star}$ \\
Secondary forests & $0.45^{\star}$ & $0.56^{\star}$ \\
Dung beetles & & \\
Undisturbed forests & -0.01 & -0.60 \\
Logged primary forests & -0.01 & -0.02 \\
Logged and burnt primary forests & $0.08^{\star}$ & $0.21^{\star}$ \\
Secondary forests & $0.30^{\star}$ & $0.43^{\star}$ \\
\hline
\end{tabular}

For species richness (richness) and compositional similarity to undisturbed forests (similarity), numbers give the proportion of variation in the biodiversity measure explained by carbon $\left(R^{2}\right.$ values) from the Bayesian piecewise linear splines (see Methods). $R^{2}$ values marked with an asterisk have $95 \%$ credible intervals that exclude zero (see Methods). Forest species were identified using the convex hull filter (see Methods).

disturbance classes. In undisturbed forests, there were no carbonbiodiversity statistical associations. In logged primary forests, carbon explained, on average, just $6 \%$ of the variation in biodiversity measures across taxa. Carbon and biodiversity were more strongly related in logged and burnt primary forests, where carbon explained, on average, $35 \%$ of biodiversity variability. In secondary forests, the carbon-biodiversity relationship was strongest, with carbon explaining an average of $57 \%$ of the variation in biodiversity levels. In disturbed forests, species richness levels recovered to those found in undisturbed forests for all taxa (Fig. 1a-d). However, the composition of species remained distinct (Fig. 1eh). This result confirms the unique conservation importance of undisturbed forests ${ }^{22,25}$ and, therefore, the need for such forests to remain a conservation priority.

The connection between disturbance intensity and carbonbiodiversity relationships was consistent among forest-species definitions, taxa and biodiversity measures. Moreover, adding environmental variables that describe site forest structure, landscape context and topoedaphic state (see Methods) to the carbonbiodiversity models made little difference to the relationships (all covariate-included model thresholds lay within the $95 \%$ credible threshold interval of the models without covariates). This indicates that our results are also likely to be robust across a broad range of environmental conditions.

Carbon-biodiversity trade-offs are greatest in the least disturbed forests. Depending on disturbance intensity, a carbonmaximization conservation strategy often led to substantial biodiversity shortfalls (Fig. 2 and Supplementary Fig. 4). Where carbon and biodiversity were not associated (for example, plants in undisturbed forests), protecting carbon-rich sites could cover many fewer species than protecting the sites with highest species richness. Conversely, where carbon and biodiversity were strongly related (for example, plants in secondary forests), biodiversity shortfalls were smaller; protecting the sites with greatest carbon was likely to capture a larger proportion of the species richness of these sites. The carbon-maximization strategy returned worse biodiversity outcomes under a more conservative conservation approach (Fig. 2e-h). When biodiversity-benefit functions are more conservative and complex - here requiring two rather than a single species occurrence across protected sites before considering a species conserved - the likelihood that a simple carbonmaximizing strategy will return good biodiversity outcomes is substantially reduced. This is particularly the case where carbonbiodiversity relationships are weak (Fig. 2).

By optimizing carbon and biodiversity together, large biodiversity gains could be achieved for small forest-carbon-protection losses (Fig. 3 and Supplementary Fig. 5). For example, when $20 \%$ of a disturbance class could be conserved, a $1 \%$ reduction in carbon produced, on average, a tenfold and eightfold greater increase, respectively, in small- and large-stemmed plant species richness in undisturbed forests (Fig. 3a,b). Differences in carbon-biodiversity trade-offs were related to the extent of the biodiversity shortfalls and, therefore, the underlying carbon-biodiversity relationships. Where a carbon-maximization strategy was relatively ineffective for biodiversity - in less disturbed, more species-rich forests large biodiversity gains could be achieved for small carbon penalties. Where a carbon-maximization strategy returned close to the highest levels of biodiversity that could be protected - in more disturbed, less species-rich forests - protecting even more biodiversity cost greater amounts of carbon. The scope for improving biodiversity outcomes without large carbon sacrifices was greater when less of the landscape could be protected. Thus, relatively small-scale carbon-focused conservation schemes - the dominant type of scheme across the tropics ${ }^{26}$ - are likely to present the greatest opportunities to improve biodiversity coverage.

In the preceding optimization analyses, we assumed constant forest conservation opportunity costs across forest-disturbance classes. However, in reality, conservation organizations must contend with the heterogeneous forgone profits landowners face when refraining from productive activities. When these opportunity costs increased with site carbon density, relative biodiversity shortfalls increased in forests with higher carbon stocks, making carbon investments in the least disturbed forests even less efficient for biodiversity than under the assumption of homogeneous opportunity costs (Fig. 4 and Supplementary Fig. 6). This finding reflects the fact that when opportunity costs increase with site carbon density, for a given budget, multiple low-carbon sites can be conserved for every high-carbon site. This pushes low-carbon forests further along the landscape coverage gradient (Fig. 2) relative to highcarbon sites, producing lower biodiversity shortfalls. For analogous reasons, when opportunity costs decreased with site carbon density, we found that relative biodiversity shortfalls decreased in higher-carbon sites, making the biodiversity efficiency of carbon conservation similar across disturbance classes.

\section{Discussion}

These findings reveal that different management strategies may be needed to ensure that carbon conservation schemes return biodiversity co-benefits across forests with different disturbance histories. In less disturbed forests ( $>100 \mathrm{Mg} \mathrm{Cha}^{-1}$ ), biodiversity levels were not statistically associated with carbon stocks (Fig. 1). This decoupling of carbon and biodiversity means that carbonfocused conservation policies may not protect the most ecologically valuable sites, especially where conservation opportunity costs increase with site carbon density. In fact, by displacing degradation pressures to lower-carbon areas, carbon investments could even jeopardize the most species-rich forests ${ }^{27}$. In more disturbed forests, carbon and biodiversity are likely to be more 


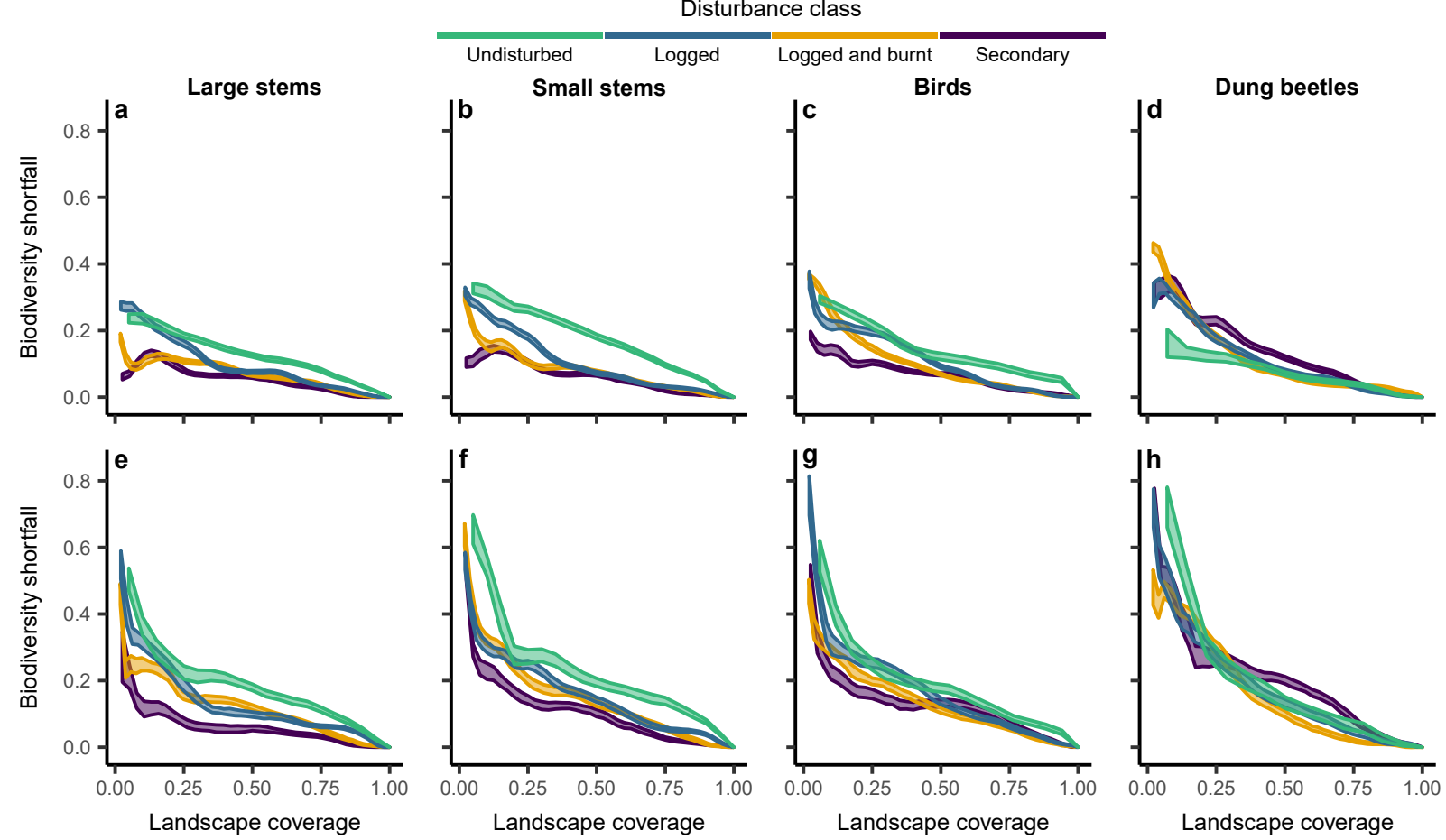

Fig. 2 Biodiversity shortfalls from a carbon-maximization strategy. a-h, The proportionate loss of species coverage when maximizing forest carbon compared with maximizing species richness over disturbance classes for large stems ( $\mathbf{a}$ and $\mathbf{e}$ ), small stems (b and $\mathbf{f}$ ), birds (c and $\mathbf{g}$ ) and dung beetles ( $\mathbf{d}$ and $\mathbf{h}$ ). Species were identified using the convex hull species filter (see Methods). A species was considered conserved if it occurred at least once (a-d) or twice (e-h) over protected sites. Error bands represent $95 \%$ confidence intervals from 100 site subsample simulations (see Methods). Landscape coverage is the proportion of the disturbance class conserved (see Methods).

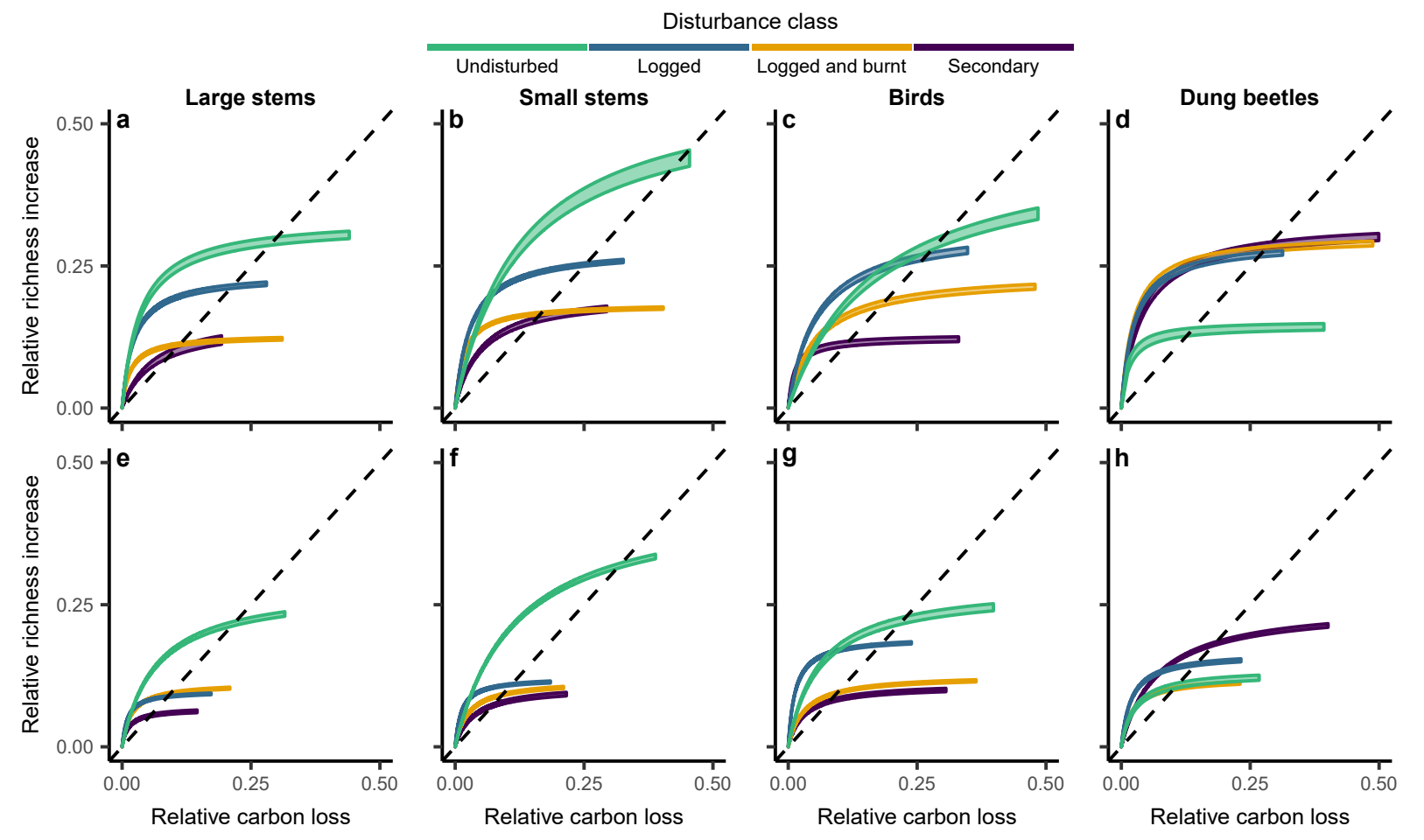

Fig. 3 | Carbon-biodiversity trade-offs. a-h, The maximum relative increase in species richness that results from a given relative reduction in forest carbon coverage when $20 \%(\mathrm{a}-\mathrm{d})$ and $40 \%(\mathrm{e}-\mathrm{h})$ of the forests in a disturbance class could be conserved for large stems (a and e), small stems (b and $\mathbf{f}$ ), birds ( $\mathbf{c}$ and $\mathbf{g}$ ) and dung beetles ( $\mathbf{d}$ and $\mathbf{h}$ ). Species were identified using the convex hull species filter (see Methods). A species was considered conserved if it occurred at least once across protected sites. Error bands represent $95 \%$ confidence intervals from 100 site subsample simulations (see Methods). Black dashed lines show the one-to-one species coverage gain to carbon loss. 

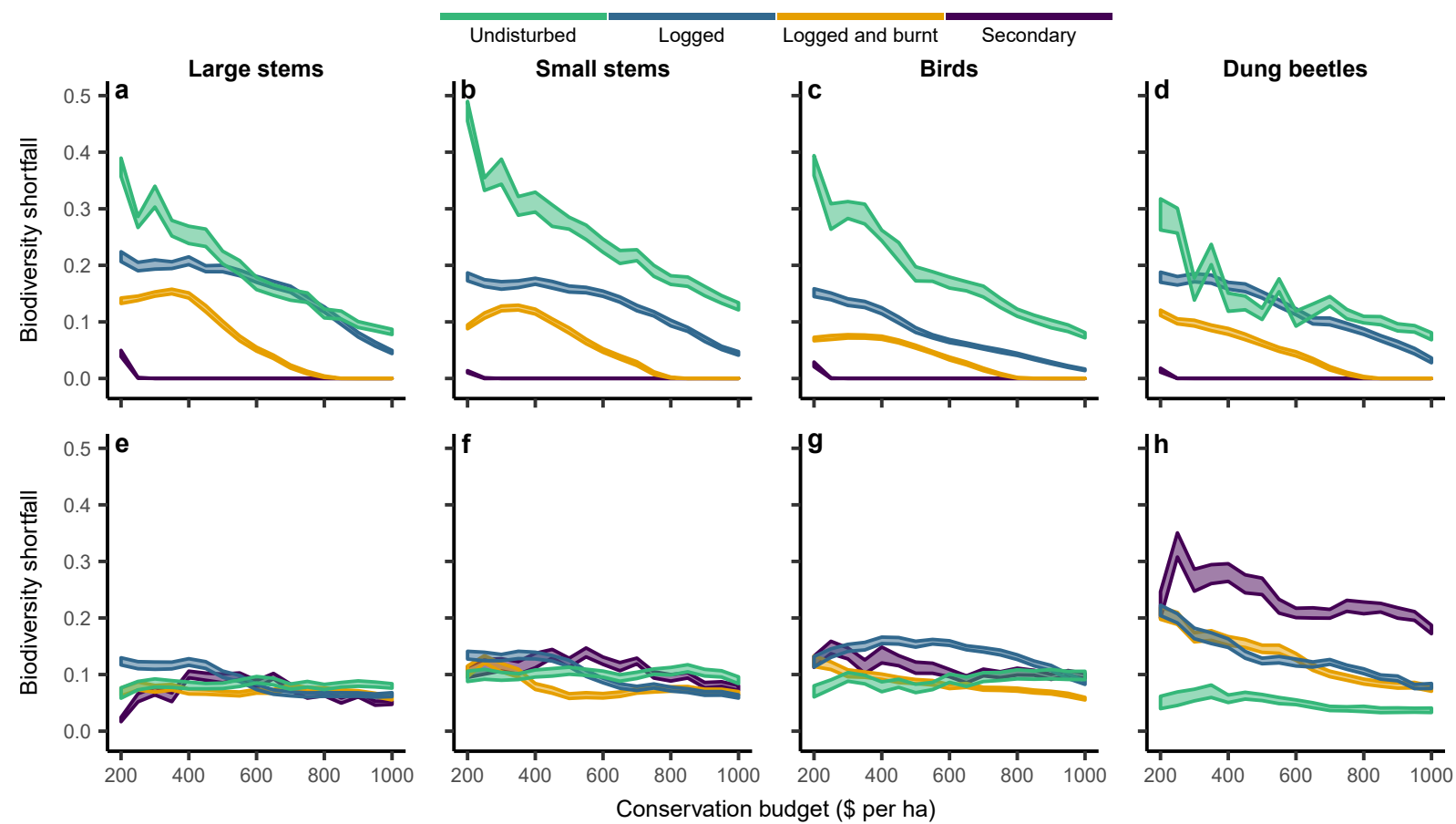

Fig. 4 | Biodiversity shortfalls when incorporating conservation opportunity costs. a-h, The proportionate loss of species coverage when maximizing forest carbon compared with maximizing species richness over disturbance classes for large stems $(\mathbf{a}$ and $\mathbf{e})$, small stems $(\mathbf{b}$ and $\mathbf{f})$, birds ( $\mathbf{c}$ and $\mathbf{g}$ ) and dung beetles ( $\mathbf{d}$ and $\mathbf{h}$ ). Species were identified using the convex hull species filter (see Methods). A species was considered conserved if it occurred at least once over protected sites. Opportunity costs per unit carbon were increasing (a-d) and decreasing (e-h) in site carbon density (see Methods). Error bands represent 95\% confidence intervals from 100 site subsample simulations (see Methods).

strongly related ${ }^{17}$. Forest restoration initiatives that seek to protect and enhance carbon stocks in degraded forests are therefore likely to protect significant proportions of their biodiversity - albeit a biodiversity that is impoverished compared with less disturbed forests (Fig. 1). This situation may also arise across all forest types where conservation opportunity costs decrease in carbon density.

Several additional factors may affect disturbance-mediated carbon-biodiversity relationships. First, the landscape configuration could act as a confounding variable ${ }^{28}$. Across disturbance classes, we found that carbon-biodiversity relationships were not affected by the inclusion of covariates describing landscape forest cover, mean nearest-neighbour distance or other aspects of the environment. This is probably due to our study regions being characterized by high levels of primary forest cover (Supplementary Fig. 1; see Methods). In more fragmented landscapes, disentangling the effects of disturbance and landscape configuration in carbon-biodiversity relationships will be key to determining appropriate management interventions. Second, spatial scale plays a fundamental role in shaping carbon-biodiversity relationships. Some studies sampling at scales finer than the present study $\left(\leq 0.1\right.$ ha) have reported positive relationships ${ }^{9,29}$. However, our cross-taxa finding of weak carbon-biodiversity relationships in less disturbed forests is consistent with similar results at larger spatial scales ${ }^{9,29}$, which are likely to be more pertinent to conservation planning 29 . At these broader scales, environmental heterogeneity may have a greater effect on local species distributions in less disturbed forests ${ }^{9,29}$. Indeed, in these forests, we found, for example, that large-stemmed plant species richness was significantly higher in sites with greater canopy cover and lower landscape land-use intensity (Supplementary Table 2). Third, tropical environmental gradients in, for example, precipitation and soil, are far larger than represented by our study sites. It remains an open question whether our results will translate to all tropical forests. Fourth, our analyses focused only on the aboveground carbon pool. A recently published study from mostly undisturbed Amazonian forests found significant, positive relationships between tree and mammal species richness and soil carbon ${ }^{30}$. An understanding of how forest disturbance impacts relationships between biodiversity and soil carbon is currently lacking. Finally, we did not consider how carbon and biodiversity benefits may accrue through carbon conservation. Where regenerating forests recover to later successional stages, conservation values will increase with time $e^{31,32}$. In contrast, our results represent the situation where future gains are fully discounted. Given the reality of idiosyncratic secondary-succession pathways ${ }^{33}$, uncertainty regarding the extent to which regenerating forests provide habitat for primary forest biodiversity ${ }^{34}$, and the increasing toll of climatechange-induced disturbances ${ }^{35}$, projecting how the future recovery of forests will impact carbon-biodiversity relationships is a challenging task.

Where our results hold, implementing forest conservation policies that account for disturbance will require that relatively undisturbed forest can be distinguished inexpensively and at large spatial extents from that which is relatively disturbed. In finding that carbon-biodiversity associations hold only in forests with less than around $100 \mathrm{Mg} \mathrm{C} \mathrm{ha-1}$, our results provide a quantitative forestdisturbance benchmark that could feasibly be measured across the tropical biome ${ }^{14}$. Future research should seek to uncover whether and where such thresholds exist in forests distinct from those in the eastern Amazon. Combining knowledge of disturbance thresholds and an understanding of how disturbance affects carbon-biodiversity relationships can greatly increase the effectiveness of attempts to mitigate both the climate and biodiversity crises. A more integrated approach to financing carbon and biodiversity conservation can help harness these opportunities. For example, to ensure that the least disturbed, most biodiverse forests are protected, existing biodiversity conservation budgets could be 
used to co-finance carbon conservation projects, offsetting reductions in carbon abatement that would result from protecting lowercarbon forests ${ }^{36}$. Biodiversity conservation organizations could also take a reactive approach to carbon conservation, protecting species-rich sites that fail to attract carbon funding ${ }^{36}$. Finally, the fact that forests of greatest conservation concern may not be effectively prioritized through carbon projects could be used to stimulate additional donor funding, internalizing the costs of generating biodiversity co-benefits into carbon conservation financing ${ }^{18}$.

\section{References}

1. Stern, N. H. The Economics of Climate Change: The Stern Review (Cambridge Univ. Press, Cambridge, 2007).

2. Global Biodiversity Outlook 4 (Convention on Biological Diversity, 2014).

3. Climate Research Roadmap Workshop: Summary Report (US Department of Energy Office of Science, 2010).

4. Dirzo, R. \& Raven, P. H. Global state of biodiversity and loss. Annu. Rev. Environ. Resour. 28, 137-167 (2003).

5. Gullison, T. A. et al. Tropical forests and climate policy. Science $\mathbf{3 1 6}$, 985-986 (2007).

6. Gardner, T. A., Barlow, J., Sodhi, N. S. \& Peres, C. A. A multi-region assessment of tropical forest biodiversity in a human-modified world. Biol. Conserv. 143, 2293-2300 (2010).

7. Parmesan, C. Ecological and evolutionary responses to recent climate change. Annu. Rev. Ecol. Evol. Syst. 37, 637-669 (2006).

8. Colwell, R. K. et al. Global warming, elevation range shifts, and lowland biotic attrition in the wet tropics. Science 322, 258-261 (2008).

9. Poorter, L. et al. Diversity enhances carbon storage in tropical forests. Glob. Ecol. Biogeogr. 24, 1314-1328 (2015).

10. Norman, M. \& Nakhooda, S. The State of REDD+ Finance Working Pape 378 (Centre for Global Development, 2014).

11. McCarthy, D. P. et al. Financial costs of meeting global biodiversity conservation targets: current spending and unmet needs. Science $\mathbf{3 3 8}$ 946-949 (2012).

12. Seymour, F. \& Busch, J. Why Forests? Why Now? The Science, Economics and Politics of Tropical Forests and Climate Change (Center for Global Development, Washington DC, 2016).

13. Asner, G. P. et al. A universal airborne LiDAR approach for tropical forest carbon mapping. Oecologia 168, 1147-1160 (2011).

14. Le Toan, T. et al. The BIOMASS mission: mapping global forest biomass to better understand the terrestrial carbon cycle. Remote Sens. Environ. 115, 2850-2860 (2011).

15. Gardner, T. A. et al. A framework for integrating biodiversity concerns into national REDD+ programmes. Biol. Conserv. 154, 61-71 (2011).

16. Phelps, J., Webb, E. L. \& Adams, W. M. Biodiversity co-benefits of policies to reduce forest-carbon emissions. Nat. Clim. Change 2, 497-503 (2012).

17. Gilroy, J. J. et al. Cheap carbon and biodiversity co-benefits from forest regeneration in a hotspot of endemism. Nat. Clim. Change 4, 503-507 (2014).

18. Phelps, J., Friess, D. A. \& Webb, E. L. Win-win REDD+ approaches belie carbon-biodiversity trade-offs. Biol. Conserv. 154, 53-60 (2012).

19. Strassburg, B. B. N. et al. Global congruence of carbon storage and biodiversity in terrestrial ecosystems. Conserv. Lett. 3, 98-105 (2010).

20. Cavanaugh, K. C. et al. Carbon storage in tropical forests correlates with taxonomic diversity and functional dominance on a global scale. Glob. Ecol. Biogeogr. 23, 563-573 (2014).

21. Beaudrot, L. et al. Limited carbon and biodiversity co-benefits for tropical forest mammals and birds. Ecol. Appl. 26, 1098-1111 (2016).

22. Gibson, L. et al. Primary forests are irreplaceable for sustaining tropical biodiversity. Nature 478, 378-381 (2011).

23. Lewis, S. L., Edwards, D. P. \& Galbraith, D. Increasing human dominance of tropical forests. Science 349, 827-832 (2015).

24. Barlow, J. et al. Anthropogenic disturbance in tropical forests can double biodiversity loss from deforestation. Nature 535, 144-147 (2016).

25. Watson, J. E. M. et al. The exceptional value of intact forest ecosystems. Nat. Ecol. Evol. 2, 599-610 (2018).

26. Panfil, S. N. \& Harvey, C. A. REDD+ and biodiversity conservation: a review of the biodiversity goals, monitoring methods, and impacts of 80 REDD+ projects. Conserv. Lett. 9, 143-150 (2016).

27. Grainger, A. et al. Biodiversity and REDD at Copenhagen. Curr. Biol. 19, R974-R976 (2009).

28. Magnago, L. F. S. et al. Would protecting tropical forest fragments provide carbon and biodiversity cobenefits under REDD+? Glob. Change Biol. 21, 3455-3468 (2015).

29. Chisholm, R. A. et al. Scale-dependent relationships between tree species richness and ecosystem function in forests. J. Ecol. 101, 1214-1224 (2013).

30. Sobral, M. et al. Mammal diversity influences the carbon cycle through trophic interactions in the Amazon. Nat. Ecol. Evol. 1, 1670-1676 (2017).

31. Dunn, R. R. Managing the tropical landscape: a comparison of the effects of logging and forest conversion to agriculture on ants, birds, and lepidoptera. For. Ecol. Manag. 191, 215-224 (2004).

32. Letcher, S. G. \& Chazdon, R. L. Rapid recovery of biomass, species richness, and species composition in a forest chronosequence in Northeastern Costa Rica. Biotropica 41, 608-617 (2009).

33. Chazdon, R. L. et al. Rates of change in tree communities of secondary Neotropical forests following major disturbances. Phil. Trans. R. Soc. Lond. B 362, 273-289 (2007).

34. Barlow, J., Mestre, L. A. M., Gardner, T. A. \& Peres, C. A. The value of primary, secondary and plantation forests for Amazonian birds. Biol. Conserv. 136, 212-231 (2007).

35. Aragão, L. E. O. C. et al. 21st century drought-related fires counteract the decline of Amazon deforestation carbon emissions. Nat. Commun. 9, 536 (2018)

36. Venter, O., Hovani, L., Bode, M. \& Possingham, H. Acting optimally for biodiversity in a world obsessed with REDD+ . Conserv. Lett. 6, 410-417 (2013)

\section{Acknowledgements}

We thank R. F. Braga, R. C. de Oliveira Jr, J. M. Silveira, F. Z. Vaz-de-Mello and R. C. S. Veiga for support with data collection, and R. A. Begotti, T. M. Cardoso, S. S. Nunes, J. V. Siqueira, C. M. Souza Jr and A. Venturieri for assistance processing the remotely sensed data. This work was supported by grants from Brazil (EMBRAPA SEG:02.08.06.005.00; CNPq 574008/2008-0, 458022/2013-6, 400640/2012-0 and PELD 441659/2016-0; CAPES scholarships; FAPESP 2012/51872-5; and The Nature Conservancy Brasil), the UK (Darwin Initiative 17-023; NE/F01614X/1; NE/G000816/1; NE/F015356/2; NE/1018123/1; NE/K016431/1; NE/N01250X/1, NE/N01250X/1; and H2020-MSCA-RISE-2015 (Project 691053-ODYSSEA)) and Formas 2013-1571, and Australian Research Council grant DP120100797. J.F. and R.P. acknowledge CNPq productivity scholarships (process numbers, respectively: 307788/2017-2 and 308205/2014-6). Institutional support was provided by the Herbário IAN in Belém and LBA in Santarém. This is paper number 66 in the Sustainable Amazon Network series.

\section{Author contributions}

T.A.G., J.B. and J.F. designed the research, with input from E.B., A.C.L., S.F.B.F., J.L.,V.H.F.O., R.R.C.S., I.C.G.V., L.E.O.C.A. and R.P. E.B., A.C.L., V.H.F.O., R.R.C.S., J.F., N.G.M. and J.L. collected the field data or analysed biological samples. S.F.B.F. and T.A.G. processed the remote sensing data. G.D.L. and J.R.T. analysed the data, with input from J.F., J.B., R.M.N., A.C.L. and T.A.G. G.D.L., J.F., J.B., T.A.G., A.C.L., R.M.N. and J.R.T. wrote the manuscript, with input from all authors.

Correspondence and requests for materials should be addressed to J.F. (joice.ferreira@embrapa.br) or G.D.L. (garethlennox@msn.com) 


\section{Methods}

Study areas and design. Our study focused on Paragominas (PGM) and Santarém (STM) in the Brazilian state of Pará ${ }^{24}$ (Supplementary Fig. 1). We divided PGM and STM into third- and fourth-order drainage catchments using a digital elevation model. A total of 18 study catchments were allocated to each region. Study sites $(10 \mathrm{~m} \times 300 \mathrm{~m}$; Supplementary Fig. 1) were distributed within catchments according to a stratified random sampling design in proportion to forest and nonforest cover, and were separated by $>$ $1.5 \mathrm{~km}$ to minimize spatial autocorrelation (see ref. 37 for further details of the experimental design).

This experimental design returned 234 forest sites, which we classified into 4 disturbance classes. We defined: undisturbed forests $(n=30 ; 13$ in PGM and 17 in STM) as areas under permanent forest cover that showed no evidence of disturbance; logged primary forests ( $n=70 ; 44$ in PGM and 26 in STM) as areas under permanent forest cover that showed signs of logging, such as logging debris; logged and burnt primary forests $(n=75 ; 44$ in PGM and 31 in STM) as areas under permanent forest cover that, in addition to showing evidence of logging, also showed signs of recent burning, such as fire scars; and secondary forests ( $n=59 ; 20$ in PGM and 39 in STM) as areas of forest regenerating on abandoned agricultural land.

Biodiversity and environmental variable surveys. Surveys were conducted in PGM and STM in 2010-2011. We sampled large-stemmed plants $(\geq 10 \mathrm{~cm}$ diameter at breast height (DBH)), small-stemmed plants $(2 \mathrm{~cm}<\mathrm{DBH}<10$ $\mathrm{cm})$, birds and dung beetles. Large-stemmed plants were sampled in a $10 \mathrm{~m} \times$ $250 \mathrm{~m}$ plot at the study site, small-stemmed plants were sampled in five $5 \mathrm{~m} \times$ $10 \mathrm{~m}$ subplots, and birds and dung beetles were sampled at 3 sampling points spanning the site (Supplementary Fig. 1; see ref. 24 for full details of the biodiversity sampling procedures). We measured site carbon density (hereafter carbon) as one half of the biomass of all sampled plants $\geq 2 \mathrm{~cm}$ DBH. The biomass of each sampled plant was estimated using allometric equations. The site value was found by summing over all plants and scaling by plot area (see ref. 38 for further details of the biomass estimation procedure).

Alongside the biodiversity surveys, we sampled a suite of environmental variables that represent a site's forest structure, landscape context and topoedaphic state. We used three variables to describe forest structure: (1) canopy cover; (2) understory stem density; and (3) liana density. Canopy cover was estimated by applying gap light analysis on hemispherical photos. Understory stem and liana densities were estimated by counting, respectively, all live plants and lianas $\geq 2 \mathrm{~cm} \mathrm{DBH}$ within the five $5 \mathrm{~m} \times 10 \mathrm{~m}$ subplots and scaling by plot area.

We used three variables to describe landscape context: (1) primary and advanced secondary forest ( $>10$ years old) cover in a $1 \mathrm{~km}$ buffer around the study site (forest cover); (2) land-use intensity in a $500 \mathrm{~m}$ buffer around the study site; and (3) the mean nearest-neighbour distance of all site pixels to a primary or advanced secondary forest edge (edge distance). Each of these variables was determined by classification of all pixels in the associated buffer using a 2010 landuse map derived by Landsat-TM image classification. Land-use intensity measures the mean time since deforestation of all pixels in the buffer ${ }^{39}$.

We used three variables to describe a site's topoedaphic state: (1) soil clay content; (2) mean slope; and (3) mean elevation of all pixels in a $100 \mathrm{~m}$ buffe around the study site. Soil clay content was estimated as the mean value from five 30-cm-deep soil profiles spanning the study site. Slope and elevation were derived from a digital elevation model.

Variation in species conservation importance. We applied two species filters to our full dataset following ref. 24. For the first species filter, we applied a two-dimensional non-metric multidimensional scaling to all forest sites based on a stem-size classification. We then defined forest species to be those that occurred at least once in sites within the minimum convex hull of undisturbed forests on the multidimensional scaling ('convex hull filter'). With this filter, our analyses focused on 1,576 of the 2,162 species we sampled. For our second species filter, we assumed a species was a forest species if it occurred in any primary forest site ('automatic filter'). With this filter, our analyses focused on 1,994 of the 2,162 species we sampled. As it provides a more rigorous definition of forest species, we present the results for the convex hull filter in the main text.

We then weighted the species that remained after this filtering exercise by life-history traits related to conservation importance. Due to a lack of information correlating dung beetle traits with conservation importance, we were only able to apply this approach for birds and large- and small-stemmed plants. For birds, we used geographic range size as our measure of conservation importance. Range size is the most important indicator of avian species threat status ${ }^{40}$ and is associated with many of the key predictors of extinction risk ${ }^{41}$. Range sizes were extracted from the BirdLife Data Zone ${ }^{42}$. For plants, we used wood density as a proxy for species importance. Wood density is negatively associated with growth rates $^{43}$ and positively associated with drought resistance ${ }^{44}$ and carbon storage potential ${ }^{45}$. Species wood densities were extracted from the Global Wood Density Database ${ }^{46}$. Where we sampled a species or genus not found in the Global Wood Density Database, we used the genus or family average. Lianas were given a nominal wood density of 0.01 .

To calculate species conservation values, we applied a linear weighting based on our measures of conservation importance. For birds and plants, we gave the species with the smallest range size or highest wood density a conservation value of 1 and that with the largest range size or lowest wood density a value of 0 . All other species conservation values were then mapped linearly between these extremes. For beetles, we assumed that all species that remained after having applied a species filter had equal conservation value.

Measuring site-level biodiversity. We used two measures of site-level biodiversity: conservation-value-weighted species richness and compositional similarity to undisturbed forest, as measured by the Sørensen similarity index. For the compositional similarity of a site to undisturbed forests, we first measured its pairwise compositional similarity to each undisturbed forest. We then took the site's compositional similarity to undisturbed forest to be the mean of the pairwise similarity values.

Bayesian statistical models. We used Bayesian piecewise linear spline models to characterize the carbon-biodiversity relationships. The full model for species richness was:

$$
y_{i}=\alpha_{\text {reg }[i]}+f_{\text {class }[i]}\left(x_{i}\right)+\delta_{\text {class }[i]}+\varepsilon_{\text {catch }[i]}+\epsilon_{i}
$$

$$
f_{\text {class }[i]}\left(x_{i}\right)=\sum_{j}^{k_{1}+1} \beta_{j}\left(x_{i}-\theta_{j}\right)_{+}+\sum_{n}^{k_{2}} \gamma_{m}^{\text {class }[i]}\left(x_{i}-\phi_{m}^{\text {class }[i]}\right)_{+}
$$

where $y_{i}$ is the richness at site $i$ with carbon value $x_{i}, \alpha_{r e g[i]}$ is a region-specific intercept, $f_{\text {class }[i]}\left(x_{i}\right)$ is a disturbance-class-specific nonlinear spline function, $\delta_{\text {class }[i]}$ is a constant deviation from the reference function associated with disturbance class class $[i]$, and $\varepsilon_{\text {catch }[i]}$ and $\epsilon_{i}$ are catchment and site-specific error terms, respectively. The spline function comprises up to $k_{1}+1$ linear coefficients, $\beta_{j}$, and corresponding knot points, $\theta_{j}$, that together define a reference function, and up to $k_{2}$ linear coefficients, $\gamma$, and corresponding knots, $\phi$, that together define a deviation function for disturbance class class $[i]$. Note that $\theta_{1}$ was fixed at the minimum carbon value and $(x)_{+}$equals $x$ if $x>0$ and is 0 otherwise. For the species compositional similarity analyses, we included an additional nonlinear geographic distance term to account for the greater expected compositional similarity of more proximate sites. No residual autocorrelation was evident for any model.

Bayesian model comparison, implemented with reversible-jump Markov chain Monte Carlo (MCMC) simulations ${ }^{47}$, was used to average multiple piecewise linear models to produce smoothed curvilinear relationships ${ }^{48}$ Specifically, the number of non-zero mean deviation parameters and the number and locations of knots were assigned hierarchical prior distributions that included zero knots as possible values. This approach is equivalent to averaging over multiple model structures with a different number and location of knots, using marginal likelihoods to weight models ${ }^{48}$. The resulting posterior distributions yield model-averaged parameter estimates and credible intervals that account for uncertainties about those differences. We present the results from models allowing up to three knots for all splines.

We derived two additional quantities from the MCMC model fitting: (1) thresholds in the carbon-biodiversity relationships; and (2) $R^{2}$ values to quantify the strength of the fitted relationships. A threshold was defined as the carbon value at which the slope of the fitted reference function first declined; that is, a carbon value above which the average rate of increase of the biodiversity response changed substantially. $R^{2}$ values were calculated as:

$$
1-\sum_{i}\left(y_{i}-\left(\bar{\alpha}+f_{c}\left(x_{i}\right)\right)\right)^{2} / \sum_{y}\left(y_{i}-\bar{y}_{c}\right)^{2}
$$

where $f_{c}$ and $\bar{y}_{c}$ are, respectively, the spline function and mean of the observed values for disturbance class $c$, and $\bar{\alpha}$ is the mean of the intercept terms. These values estimate the proportion of within-class variation explained by the fitted carbon-biodiversity function.

Posterior means and $95 \%$ credible intervals for all model parameters and derived quantities were estimated from 100,000 reversible-jump MCMC iterations after 20,000 burn-in iterations. Chain-history and Gelman-Rubin statistics confirmed adequate MCMC mixing and convergence ${ }^{49}$.

We used a Bayesian variable selection model with nonlinear covariate effects to explore the relationships between environmental variables and species richness (see ref. 48 for full model details). The relative importance of 
an environmental variable was assessed by the posterior probability of a non-zero effect. We considered values of this posterior probability $>0.75$, which corresponds to an odds ratio of 3 , to indicate that an environmental variable was significantly related to species richness.

Biodiversity shortfalls. We used two optimization procedures to determine the biodiversity shortfalls. First, we maximized the carbon content of protected sites without consideration of biodiversity levels (hereafter, the carbon-maximization strategy). We then maximized species richness over protected sites without consideration of carbon levels (hereafter, the biodiversity-maximization strategy). We measured the shortfall in biodiversity coverage that results from a carbon-maximization strategy compared with a biodiversity-maximization strategy (hereafter biodiversity shortfall) as the relative difference in species richness over protected sites.

The carbon-maximization strategy solved the following optimization problem:

$$
\begin{gathered}
\max \sum_{i \in I} v_{i} x_{i} \\
\max \sum_{i \in I} c_{i} x_{i} \leq B
\end{gathered}
$$

where $x_{i}$ is a binary variable that takes the value 1 if site $i$ from the set of candidate sites $I$ is protected and is 0 otherwise, $v_{i}$ is the carbon value of site $i$ expressed in $\mathrm{Mg} \mathrm{ha}^{-1}, c_{i}$ is the opportunity costs of site $i$, and $B$ is the conservation budget. Objective (2) maximizes the carbon content of protected sites subject to constraint (3), which ensures that the total opportunity costs of conserved sites is less than or equal to the budget.

The biodiversity-maximization strategy was formulated as a maximum coverage problem ${ }^{50}$ :

$$
\begin{gathered}
\max _{j \in J} w_{j} y_{j} \\
\sum_{i \in N_{j}} x_{i} \geq p_{\min } \times y_{j} \quad \forall j \in J \\
\sum_{i \in I} c_{i} x_{i} \leq B
\end{gathered}
$$

where, in addition to the variables defined above, $y_{i}$ a binary variable that takes the value 1 if species $j$ from the set of all observed species $J$ is represented on a protected site, $w_{j}$ is the conservation value of species $j$, and $N_{j}$ is the subset of all sites $I$ that contain species $j$. The variable $p_{\text {min }}$ represents the minimum number of species occurrences required among protected sites before a species is considered conserved. Constraint (5) ensures that a species is considered conserved only if at least $p_{\min }$ sites in which it was observed are protected. Objective (4) maximizes the conservation value-weighted species richness.

By eliminating the possibility of conserving single individuals or isolated populations, increasing $p_{\min }$ above its minimum value of 1 makes the conservation organization more conservative in its approach to species conservation. However, for values of $p_{\min }>1$, species observed less frequently than $p_{\min }$ cannot be protected. Therefore, to evaluate how the biodiversity outcomes of carbon conservation schemes may be affected by more conservative species-conservation approaches while continuing to ensure that rare species can be protected, we considered cases in which $p_{\text {min }}$ was set to one and two.

Let species richness over protected sites with a carbon-maximization and biodiversity-maximization strategy be, respectively $s$ and $S$. The biodiversity shortfall is then $(S-s) / S$.

Carbon-biodiversity trade-offs. To investigate carbon-biodiversity trade-offs, we developed a two-step optimization procedure. In step one, we undertook the biodiversity-maximization and carbon-maximization strategies detailed above to calculate the maximum number of species that could be covered in protected sites and the number incidentally covered when maximizing carbon. In step two, we ran an optimization that maximized carbon while constrained to cover at least a given number of species. We iteratively increased the number of species that had to be covered between the minimum and maximum values determined in step one, allowing us to calculate the minimum loss of carbon that resulted from a unit increase in richness over the range of coverage values. In other words, we used this two-step optimization procedure to trace optimal carbon-biodiversity trade-off curves.

Step one of the optimization procedure solved the optimization problems given by (2)-(6) above. Step two solved the following problem:

$$
\begin{gathered}
\max \sum_{i \in I} v_{i} x_{i} \\
\sum_{j \in J} y_{j} \geq Y \\
\sum_{i \in N_{j}} x_{i} \geq p_{\min } \times y_{j} \quad \forall j \in J \\
\sum_{i \in I} c_{i} x_{i} \leq B
\end{gathered}
$$

where, in addition to the variables defined above, $Y=\{k \in \mathbb{Z} \mid s<k<S\}$. In other words, we maximized the carbon content of protected sites (objective (7)) while constrained to ensure that at least Y species were covered (constraint (8)), and $Y$ ranges from the minimum richness returned in the carbon-maximization strategy, $s$, to the maximum returned in the biodiversity maximization strategy, $S$.

In the trade-off analyses, we assumed that one species occurrence in protected sites was sufficient to consider a species conserved (that is, $p_{\min }=1$ ), and we show relative trade-offs; that is, the relative increase in species coverage that follows from a given relative carbon-coverage reduction. All optimizations were formulated as mixed-integer programming problems, and global optimal solutions were found using branch and cut solvers.

Incorporating conservation costs. We incorporated variation in conservation opportunity costs in two idealized scenarios. First, we assumed that opportunity costs per unit of carbon increase nonlinearly with site carbon density. This may arise when the most profitable alternative land use is timber extraction. To model this scenario in an ecologically plausible way, we assumed that opportunity costs per unit of carbon followed a logistic growth curve in carbon density, $K /\left(1+A e^{-t v}\right)$, parameterized with $K=100$ (the maximum per $\mathrm{Mg}$ carbon cost), $A=100$ and $t=0.03$. With this model, carbon-poor sites, which are largely devoid of economically valuable trees, have near-zero conservation opportunity costs per unit of carbon. Opportunity costs then rise in mid-successional sites due to the influx of late-successional, economically valuable species. The growth rate of opportunity costs per unit of carbon then decreases in late-successional sites because any growth in carbon density is likely to be shared among the fixed distribution of species that are and are not of economic value.

Second, we assumed that opportunity costs per unit of carbon decrease in carbon density. We modelled this as a linear function, parametrized with our own data such that the site with the lowest carbon density was given the maximum per $\mathrm{Mg}$ carbon opportunity costs $K=100$. The site with the maximum carbon density was given per unit of carbon opportunity costs of $K / v_{\max }$ and all other site opportunity costs per unit of carbon were mapped linearly between these points.

Accounting for variation in site numbers. Given variation in site number and spatial extent across disturbance classes, optimization results could be confounded by sampling artefacts. We controlled for this in several ways. In the biodiversity shortfalls analyses with homogeneous opportunity costs, as well as giving relative figures, we present shortfall values in relation to the proportion of sites protected in each disturbance class, which we refer to as the 'landscape coverage'. In the trade-off analyses, we also show relative figures, and we set the number of sites that could be conserved relative to the number of sites in each disturbance class. For a realistic conservation scenario, we set the percentage of the landscape that could be covered to $20 \%$ for each disturbance class. For an ambitious conservation scenario, we increased this value to $40 \%$. Finally, in the biodiversity shortfalls analysis with heterogeneous opportunity costs, we first set the budget for the disturbance class with the largest average opportunity costs. For another disturbance class, we then set the equivalent budget to be the budget for the class with the highest average opportunity costs multiplied by its number of sites relative to the number of sites in the class with the highest opportunity costs. For example, if a class had twice as many sites as the class with the highest average opportunity costs, its equivalent budget was twice as large.

Assessing variance in optimization results. We used our sample data to assess variation in optimization outcomes. Because carbon and species richness have different benefit structures (additive versus complementary), in a standard bootstrap with replacements, oversampled sites, which have identical species distributions, would have no added biodiversity value but added carbon value. Therefore, applying a standard bootstrap could overestimate the biodiversity ineffectiveness of a carbon-maximization strategy. Thus, we assumed that oversampled sites had no added carbon as well as no added biodiversity value. This is equivalent to assessing variability in outcomes by taking random subsamples of the data. To ensure a sufficient 
sample across disturbance classes, we set the random subsample to contain $70 \%$ of the sites.

For each optimization problem, we ran 100 simulations with random site subsamples. For the biodiversity shortfalls analysis, we constructed $95 \%$ confidence intervals as the mean over simulations \pm 1.96 times the standard error of the mean. For the trade offs analysis, we used nonlinear least squares to fit functions of the form $a x /(1+b c)$, where $a$ and $b$ are estimated from the data and $x$ is the relative carbon loss. Being monotonically increasing and marginally decreasing, these functions have the properties of trade-off curves, and we constructed $95 \%$ confidence intervals using the parameter estimates and 1.96 times the standard error of the parameter estimates.

\section{References}

37. Gardner, T. A. et al. A social and ecological assessment of tropical land uses at multiple scales: the Sustainable Amazon Network. Phil. Trans. R. Soc. Lond. B. 368, 20120166 (2013).

38. Berenguer, E. et al. A large-scale field assessment of carbon stocks in human-modified tropical forests. Glob. Change Biol. 20, 3713-3726 (2014).

39. Ferraz, S. F. B., Vettorazzi, C. B. \& Theobald, D. M. Using indicators of deforestation and land-use dynamics to support conservation strategies: a case study of central Rondônia, Brazil. For. Ecol. Manag. 257, 1589-1595 (2009)

40. Purvis, A., Gittleman, J. L., Cowlishaw, G. \& Mace, G. M. Predicting extinction risk in declining species. Proc. Biol. Sci. 267, 1947-1952 (2000).

41. Harley, R. \& Kuin, W. E. Scale Dependency of Rarity, Extinction Risk, and Conservation Priority. Cons. Biol. 17, 1559-1570 (2003).

42. Data Zone (BirdLife International, 2017); http://datazone.birdlife.org/home

43. King, D. A. et al. The role of wood density and stem support costs in the growth and mortality of tropical trees. J. Ecol. 94, 679-680 (2006).

44. Phillips, O. L. et al. Drought sensitivity of the Amazon rainforest. Science 323, 1344-1347 (2009).

45. Baker, T. R. et al. Variation in wood density determines spatial patterns in Amazonian forest biomass. Glob. Change Biol. 10, 545-562 (2004).

46. Zanne A. E. et al. Dryad Data from: Towards a worldwide wood economics spectrum. (Dryad Digital Repository, 2009); https://doi. org/10.5061/dryad.234

47. Lunn, D. J., Best, N. \& Whittaker, J. C. Generic reversible jump MCMC using graphical models. Stat. Comput. 1, 395-408 (2009).

48. Thomson, J. R. et al. Bayesian change point analysis of abundance trends for pelagic fishes in the upper San Francisco Estuary. Ecol. Appl. 20, 1431-1448 (2010).

49. Brooks, S. P. \& Gelman, A. General methods for monitoring convergence of iterative simulations. J. Comput. Graph. Stat. 7, 434-455 (1998).

50. Church, R. L., Stoms, D. M. \& Davis, F. W. Reserve selection as a maximal covering location problem. Biol. Conserv. 7, 105-112 (1996). 

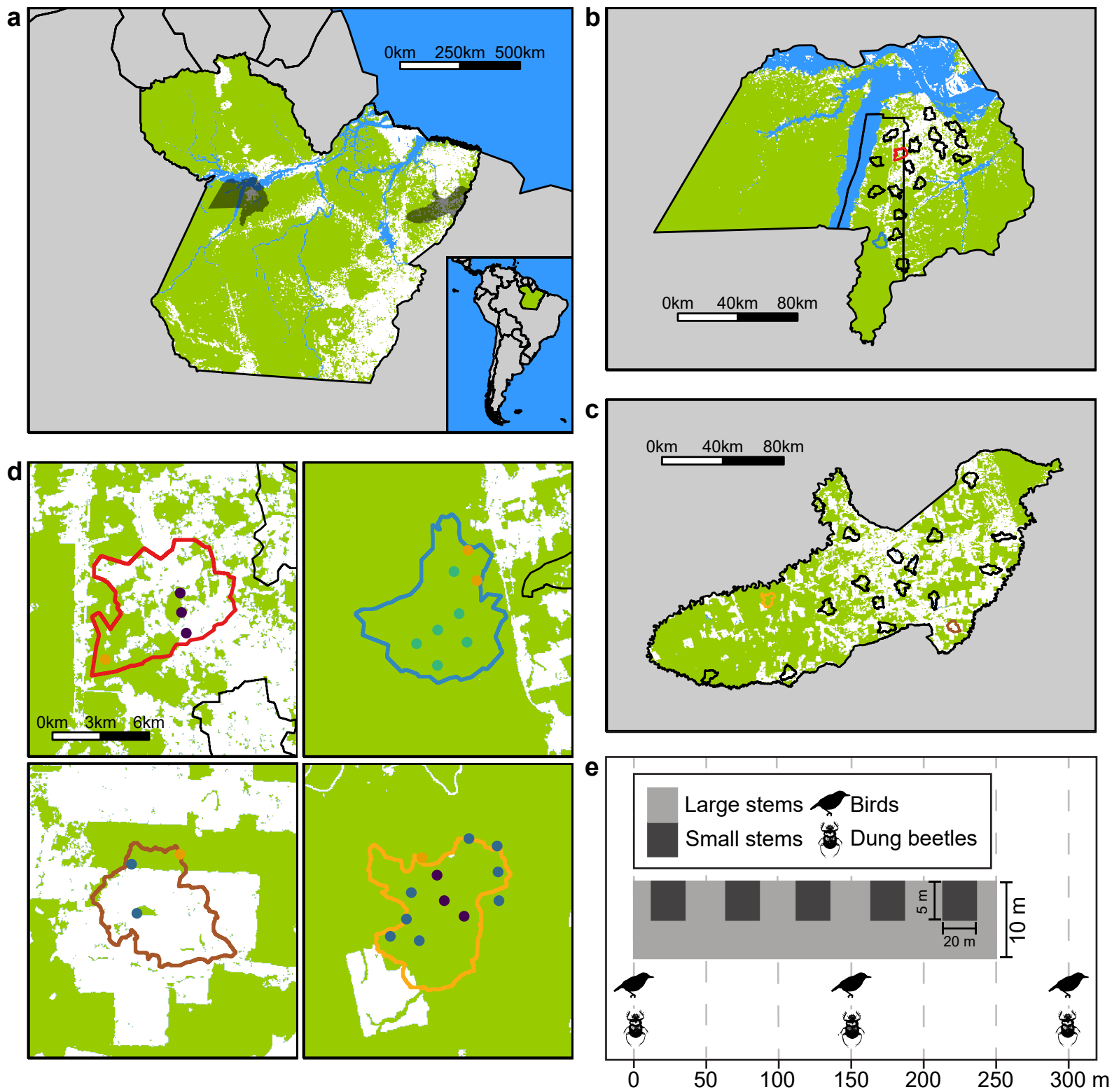

Fig. S1 Study area and design. a, The distribution of forest in c. $10 \mathrm{~km}^{2}$ cells across Pará. A cell was considered to be forest (light green) if the sum of primary and secondary forest area was greater than $50 \%$ of the land area. The locations of Santarém (in the west) and Paragominas (in the east) are shown in silhouette. The distribution of forest in c. $1 \mathrm{~km}^{2}$ cells across Santarém (b) and Paragominas (c). Also shown in these panels is the distribution of the study catchments. $\mathbf{d}$, The distribution of study sites in four example catchments in Santarém and Paragominas. Undisturbed forest sites are shown in dark green circles, logged primary forest sites in blue circles, logged and burnt primary forest sites in orange circles, and secondary forest sites in purple circles. e, Floral and faunal sampling within the study sites. 

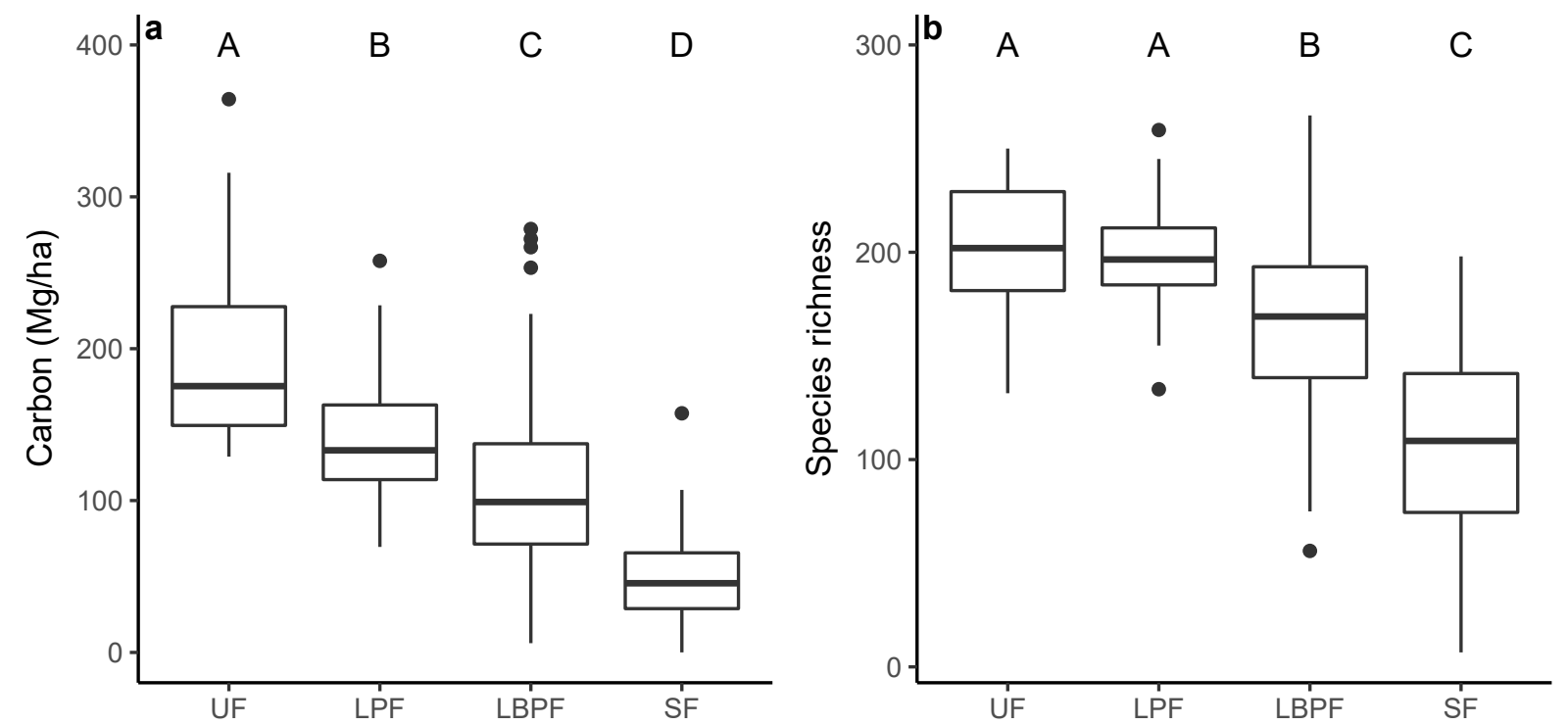

Fig. S2 | The distribution of carbon and species richness. The distribution of carbon (a) and species richness (b) in sites with different histories of anthropogenic disturbance. Species were identified with the convex hull species filter (see Methods). Boxplots show the median and interquartile range. Letters above the groups show the results for pair-wise comparisons of group means using Tukey's range test. Groups that have different letters have statistically different means $(p<0.05)$. UF, undisturbed forests. LPF, logged primary forests. LBPF, logged and burnt primary forests. SF, secondary forests. 
Disturbance class
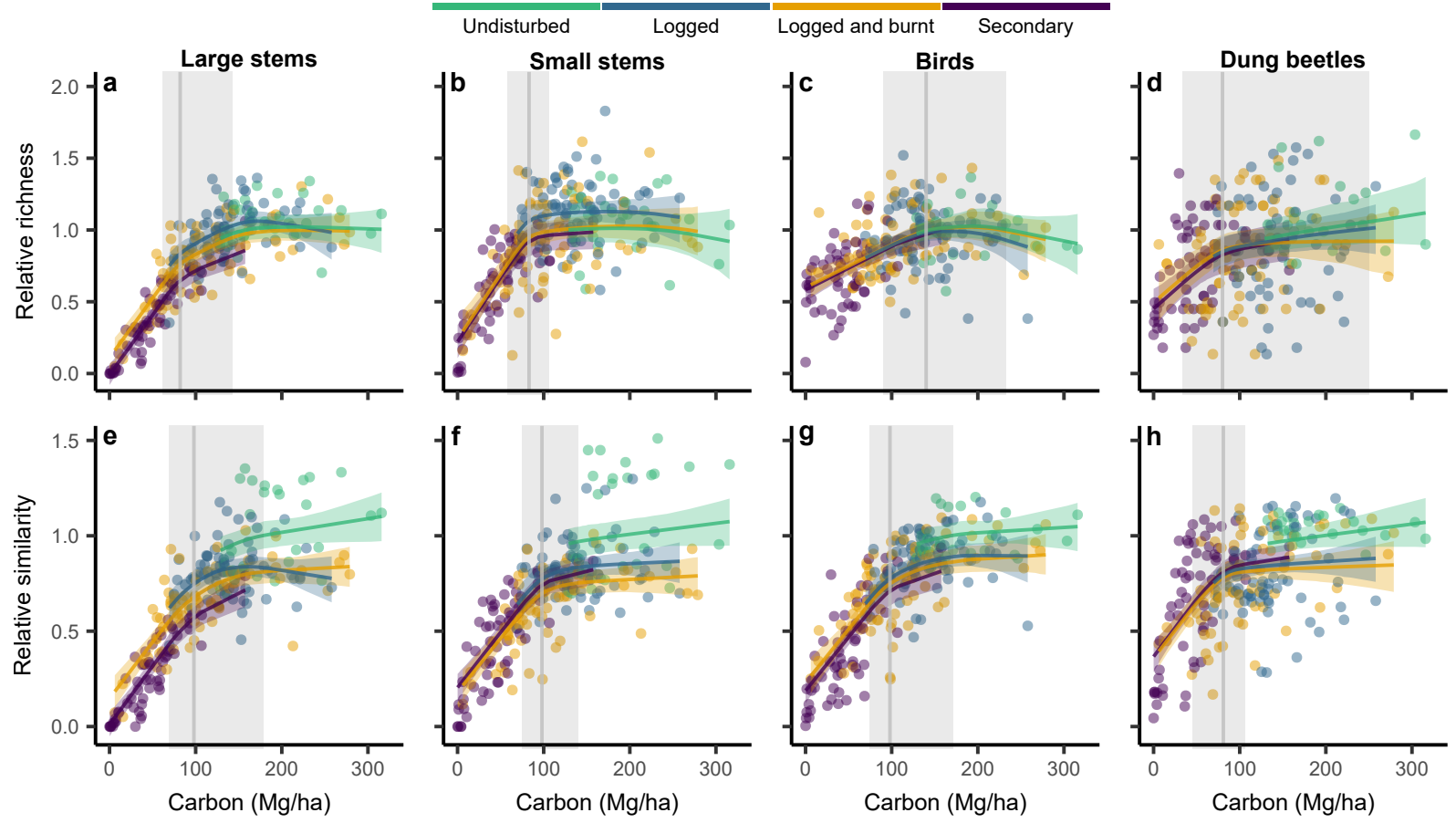

Fig. S3 | Carbon-biodiversity relationships in human-modified forests. a-h, The relationship between forest carbon levels and species richness (a-d) and compositional similarity to undisturbed forest (e-h) over disturbance classes for large stems (a and e), small stems (b and $\mathbf{f})$, birds ( $\mathbf{c}$ and $\mathbf{g}$ ) and dung beetles ( $\mathbf{d}$ and $\mathbf{h}$ ). Species were identified using the automatic species filter (see Methods). Richness and similarity values are given relative to their respective mean value in undisturbed forests. Points show the site values. Lines show the Bayesian piecewise linear splines. Error bands show 95\% credible intervals (see Methods). The grey vertical lines show the threshold estimate at which carbon-biodiversity relationships breakdown (see Methods). The grey window is the $95 \%$ threshold credible interval. 
Disturbance class
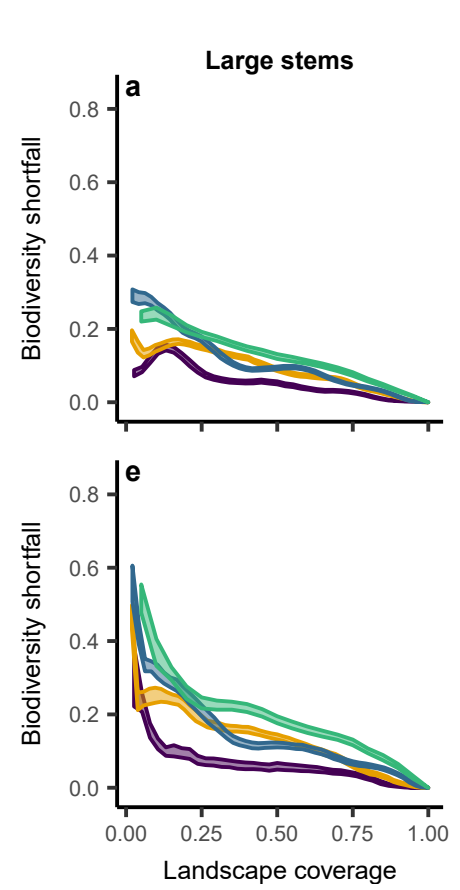
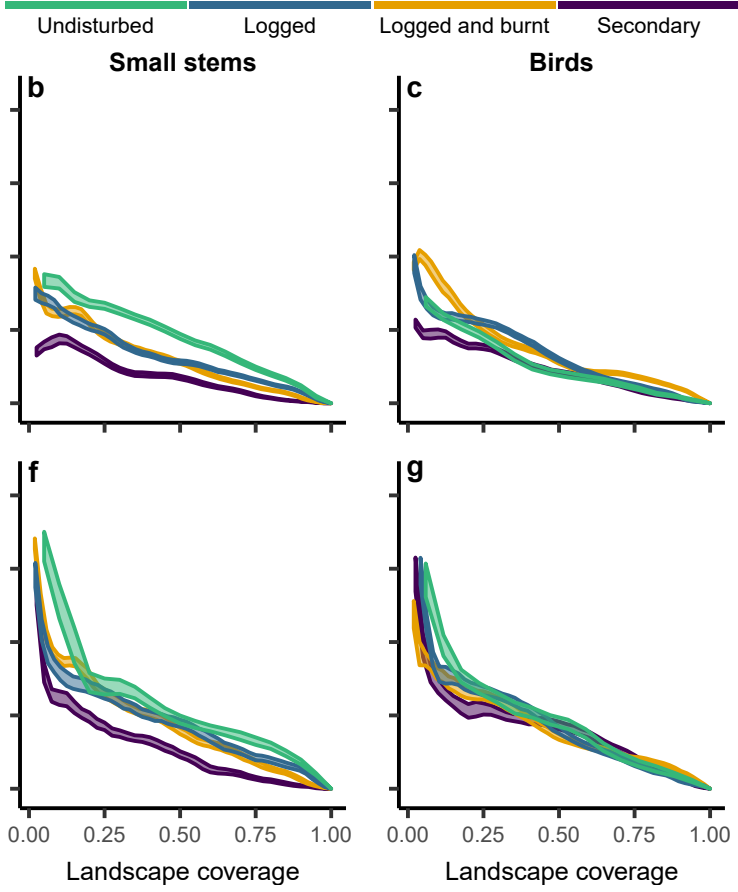

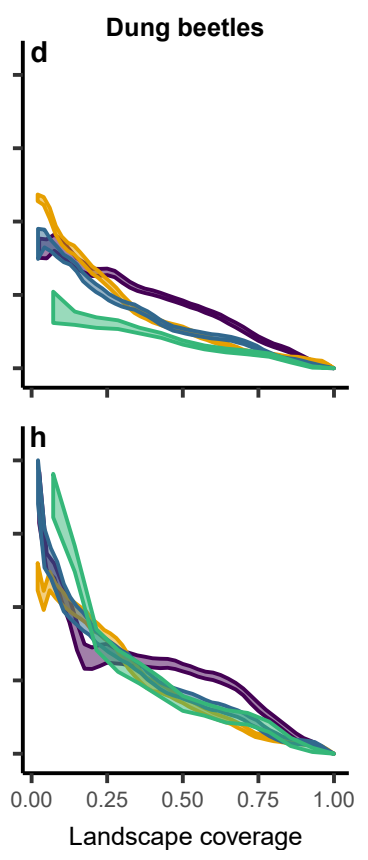

Fig. S4 Biodiversity shortfalls from a carbon-maximization strategy. $\mathbf{a}-\mathbf{h}$, The proportionate loss of species coverage when maximizing forest carbon compared with maximizing species richness over disturbance classes for large stems (a and e), small stems (b and f), birds (c and $\mathbf{g}$ ) and dung beetles ( $\mathbf{d}$ and $\mathbf{h}$ ). Species were identified using the automatic species filter (see Methods). A species was considered conserved if it occurred at least once (a-d) or twice (e-h) over protected sites. Error bands represent $95 \%$ confidence intervals from 100 site subsample simulations (see Methods). Landscape coverage is the proportion of the disturbance class conserved (see Methods). 
Disturbance class
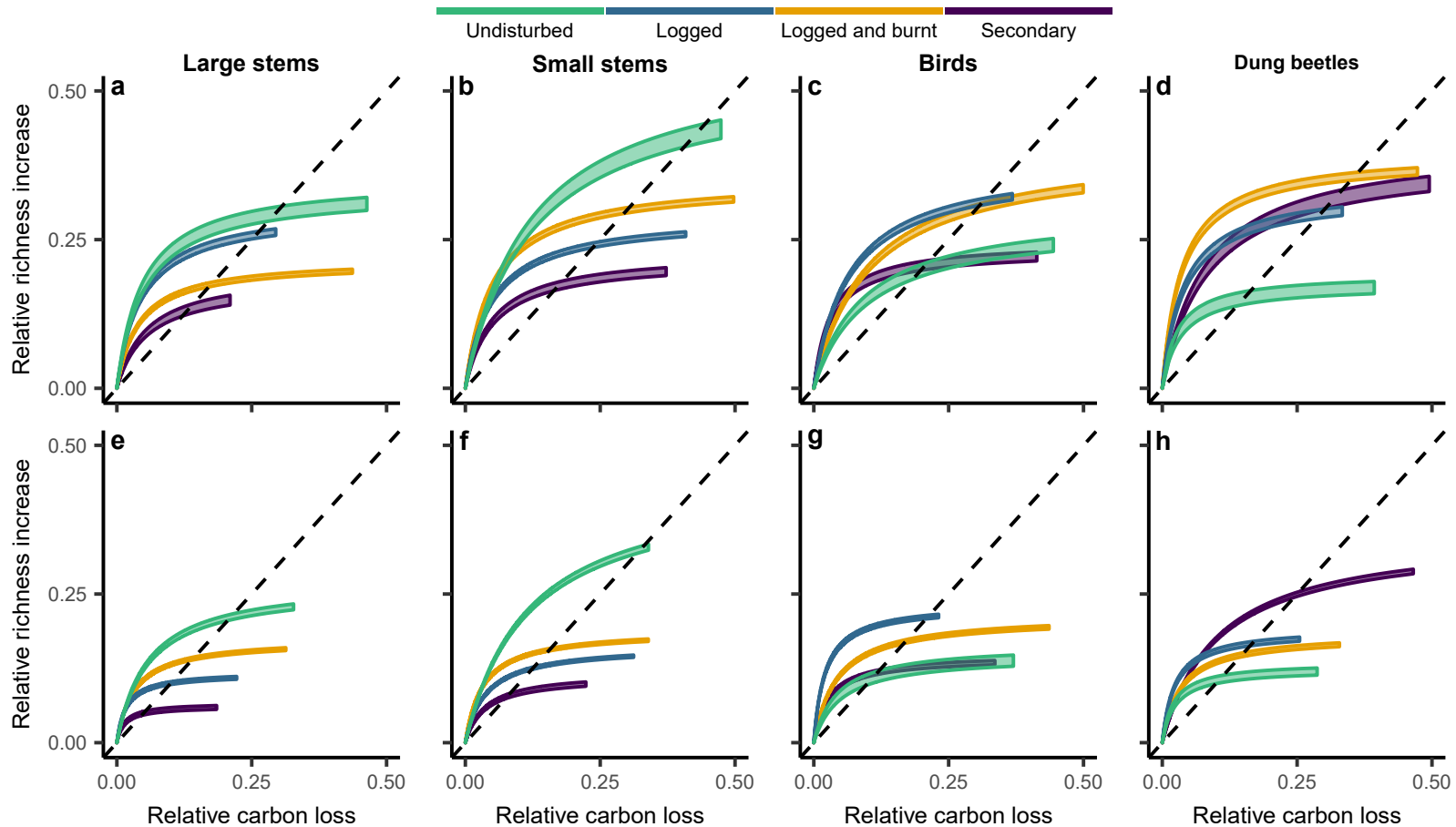

Fig. S5 Carbon-biodiversity trade-offs. a-h, The maximum relative increase in species richness that results from a given relative reduction in forest carbon coverage when $20 \%$ (a-d) and $40 \%$ (e-h) of the forests in a disturbance class could be conserved for large stems (a and e), small stems ( $\mathbf{b}$ and $\mathbf{f}$ ), birds ( $\mathbf{c}$ and $\mathbf{g}$ ) and dung beetles ( $\mathbf{d}$ and $\mathbf{h}$ ). Species were identified using the automatic species filter (see Methods). A species was considered conserved if it occurred at least once across protected sites. Error bands represent $95 \%$ confidence intervals from 100 site subsample simulations (see Methods). Black dashed lines show the one-to-one species coverage gain to carbon loss. 


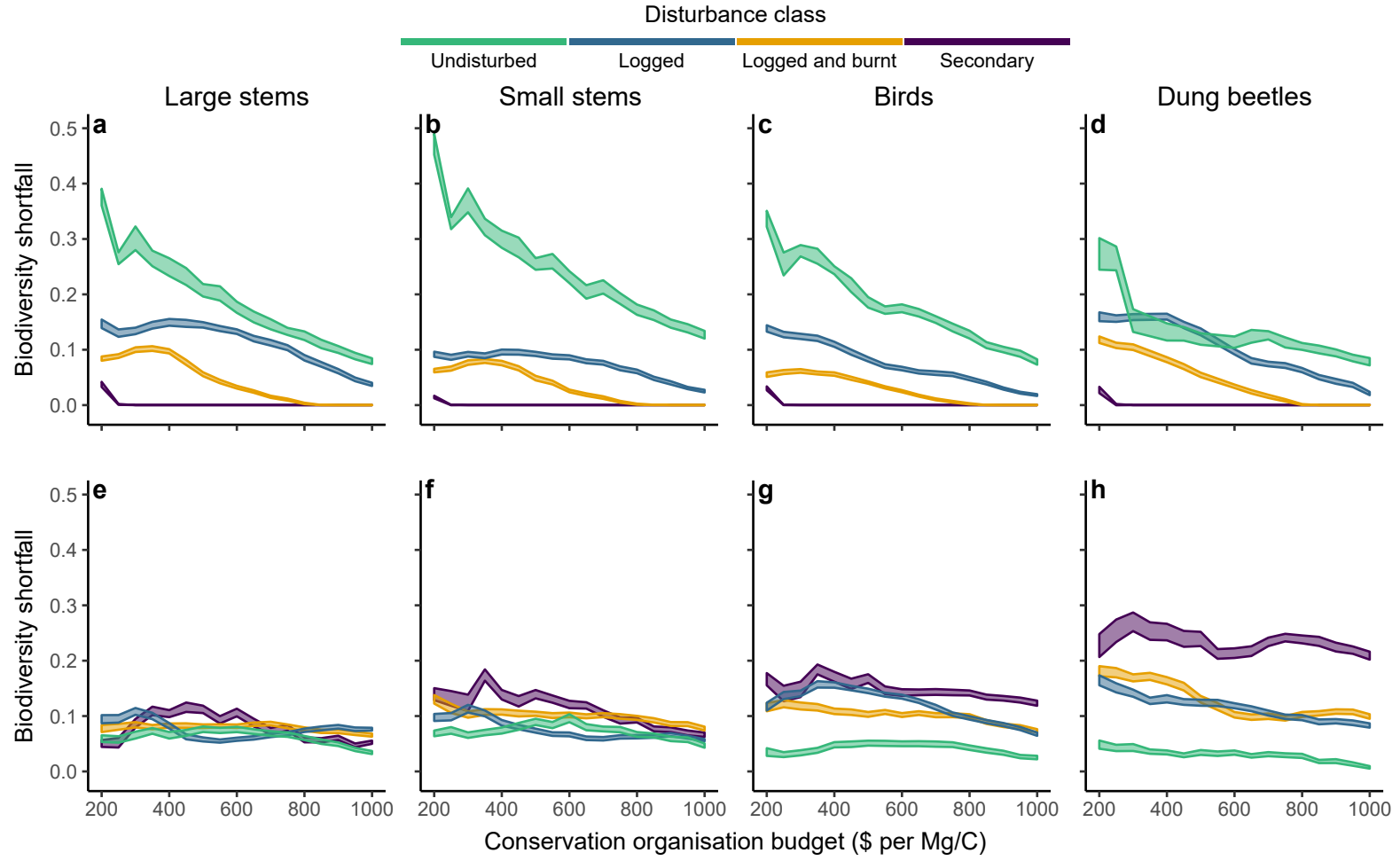

Fig. S6 | Biodiversity shortfalls when incorporating conservation opportunity costs. a-h, The proportionate loss of species coverage when maximizing forest carbon compared with maximizing species richness over disturbance classes for large stems (a and e), small stems (b and $\mathbf{f})$, birds ( $\mathbf{c}$ and $\mathbf{g}$ ) and dung beetles ( $\mathbf{d}$ and $\mathbf{h})$. Species were identified using the automatic species filter (see Methods). A species was considered conserved if it occurred at least once over protected sites. Opportunity costs per unit carbon were increasing (a-d) and decreasing (e-h) in site carbon density (see Methods). Error bands represent $95 \%$ confidence intervals from 100 site subsample simulations (see Methods). 
Table S1 | Carbon as a predictor of biodiversity in human-modified tropical landscapes.

\section{Richness Similarity}

\section{Large stems}

UF

0.00

$0.13^{*}$

LPF

$0.25^{*}$

0.05

LBPF

$0.60^{*}$

$0.57^{*}$

SF

$0.84^{*}$

$0.79^{*}$

Small stems

$\begin{array}{lll}\text { UF } & 0.01 & 0.06 \\ \text { LPF } & -0.01 & 0.00 \\ \text { LBPF } & 0.29^{*} & 0.49^{*} \\ \text { SF } & 0.66^{*} & 0.61^{*}\end{array}$

Birds

UF

0.01

0.05

LPF

0.01

$0.11^{*}$

LBPF

$0.09^{*}$

$0.41^{*}$

SF

$0.23^{*}$

$0.58^{*}$

Dung beetles

$\begin{array}{lll}\text { UF } & -0.01 & -0.65 \\ \text { LPF } & -0.01 & 0.03 \\ \text { LBPF } & 0.05 & 0.23^{*} \\ \text { SF } & 0.23^{*} & 0.44^{*}\end{array}$

For species richness (Richness) and compositional similarity to undisturbed forests (Similarity), figures give the proportion of variation in the biodiversity measure explained by carbon $\left(R^{2}\right.$ values) from the Bayesian piecewise-linear splines (see Methods). $R^{2}$ values marked with an asterisk have $95 \%$ credible intervals that exclude zero (see Methods). UF, undisturbed forests. LPF, logged primary forests. LBPF, logged-and-burnt primary forests. SF, secondary forests. Forest species were identified using the automatic filter (see Methods). 
Table S2| The strength of association between species richness and environmental variables in tropical forests

\begin{tabular}{|c|c|c|c|c|}
\hline & Large stems & Small stems & Birds & Beetles \\
\hline \multicolumn{5}{|l|}{ All forests } \\
\hline Canopy cover & $1.00^{*}(+)$ & $1.00^{*}(+)$ & $0.78^{*}(+)$ & $1.00^{*}(+)$ \\
\hline Clay & 0.18 & 0.26 & 0.27 & 0.25 \\
\hline Edge distance & 0.28 & 0.18 & 0.27 & 0.34 \\
\hline Elevation & 0.13 & 0.21 & 0.43 & 0.27 \\
\hline Forest cover & $0.90^{*}(+)$ & 0.38 & $0.99^{*}(+)$ & $0.79^{*}(+)$ \\
\hline Liana density & $0.98^{*}(+)$ & $1.00^{\star}(+)$ & 0.43 & 0.27 \\
\hline LUI & $1.00^{*}(-)$ & $1.00 *(-)$ & 0.68 & 0.36 \\
\hline Slope & 0.20 & 0.23 & 0.34 & 0.27 \\
\hline Stem density & $1.00^{*}(+)$ & $0.99^{*}(+)$ & 0.57 & $0.89^{*}(+)$ \\
\hline \multicolumn{5}{|c|}{ Less disturbed forests (> $100 \mathrm{Mg} \mathrm{C/ha)}$} \\
\hline Canopy cover & $0.96^{*}(+)$ & $0.92^{*}(+)$ & 0.42 & 0.43 \\
\hline Clay & 0.63 & 0.38 & 0.40 & 0.41 \\
\hline Edge distance & 0.37 & 0.28 & 0.41 & 0.44 \\
\hline Elevation & 0.27 & 0.40 & 0.45 & 0.45 \\
\hline Forest cover & 0.49 & 0.30 & 0.56 & 0.45 \\
\hline Liana density & 0.58 & 0.46 & 0.48 & 0.37 \\
\hline LUI & $0.78^{*}(-)$ & 0.52 & 0.46 & 0.41 \\
\hline Slope & 0.33 & 0.24 & 0.42 & 0.43 \\
\hline Stem density & 0.37 & $1.00^{*}(+)$ & 0.46 & 0.45 \\
\hline \multicolumn{5}{|c|}{ More disturbed forests (<100 Mg C/ha) } \\
\hline Canopy cover & $1.00^{*}(+)$ & $1.00^{*}(+)$ & 0.41 & $0.91^{*}(+)$ \\
\hline Clay & 0.51 & 0.31 & 0.58 & 0.41 \\
\hline Edge distance & 0.28 & 0.61 & 0.44 & 0.41 \\
\hline Elevation & 0.31 & 0.28 & 0.41 & 0.40 \\
\hline Forest cover & 0.30 & 0.28 & 0.41 & 0.36 \\
\hline Liana density & 0.34 & $0.95^{\star}(+)$ & 0.58 & 0.49 \\
\hline LUI & 0.26 & 0.28 & 0.44 & 0.32 \\
\hline Slope & 0.28 & 0.27 & 0.42 & 0.68 \\
\hline Stem density & 0.30 & 0.31 & 0.61 & 0.48 \\
\hline
\end{tabular}

The strength of the association between species richness and an environmental variable was defined by the posterior probability of a non-zero effect (See Methods). Association strengths $>0.75$ were considered significant. For significant variables, the direction of the relationship is given in brackets 